\title{
A rare Meckel's diverticulum complication in inguinal hernia: case report of Littre hernia
}

\author{
๑Dafer Şenol, (1)Taygun Gülşen \\ Sultan Abdulhamid Han Training and Research Hospital, Department of General Surgery, Istanbul, Turkey
}

Cite this article as: Şenol Z, Gülşen T. A rare Meckel's diverticulum complication in inguinal hernia: case report of Littre hernia. Anatolian Curr Med J 2021; 3(1): 72-74.

\begin{abstract}
Meckel's diverticulum (MD) is the most common congenital abnormality of the gastrointestinal ductus resulted from incomplete closure of the omphalomesenteric tube between 5th-7th intrauterine week. The incidence of MD is reported to be around $2 \%$ in the general population. $\mathrm{MD}$ is generally asymptomatic during life and symptoms are observed in around $1 \%$ of patients. MD is rarely found within hernial sac which is known as Littre hernia (LH). The incidence of this extremely rare condition, $\mathrm{LH}$, is less than $1 \%$ in all MD cases. It is difficult to diagnose LH preoperatively. A 63-year-old male patient applied to our hospital with the complaints of swelling in both of his inguinal regions for the last six months. In the right hernia sac of the patient, MD was seen which became evident during surgery. In this study, this very rare MD case observed and treated in our patient and known in the literature as a Littre hernia is presented.
\end{abstract}

Keywords: Meckel's diverticulum, inguinal hernia, hernia sac, Littre hernia

\section{INTRODUCTION}

Meckel's diverticulum (MD) is the most common congenital abnormality of the gastrointestinal tract and its incidence is reported to be approximately $2 \%$ in the population. MD is rarely observed within hernial sac which is known as Littre hernia (LH). This unusual condition, $\mathrm{LH}$, is seen in less than $1 \%$ of all MD cases. It is difficult to diagnose LH preoperatively. In this study, the treatment of a $\mathrm{LH}$ case which only became evident during surgery in a male patient is presented and examined together with other cases in the literature.

\section{CASE}

A 63-year-old male patient applied to our hospital with the complaints of swelling in both of his inguinal regions for the last six months. As a result of medical examinations, bilateral inguinal hernia was diagnosed. After necessary operation preparations, elective surgery was performed. The presence of MD in the hernial sac, which is a very rare condition, was observed in the right hernia sac of our patient. Images of Littre hernia observed and reduced during the surgery are shown in Figure 1.

The mainstay of treatment is surgery. Due to the absence of strangulation and infection, no additional surgical procedure was carried out, and hernia repair was performed with the appropriate technique.

\section{DISCUSSION}

Meckel's diverticulum is the most prevalent congenital abnormality of the gastrointestinal tract and its incidence is approximately $2 \%$ in the general population (1). The diverticulum develops from the incomplete closure of the omphalomesenteric duct during the fifth to seventh weeks of the embryonic development. MD was firstly reported by Guilhelmus Fabricius Hildanus in 1598, but the first complete and detailed recognition of this anomaly was done by Johann Friedrich Meckel in 1809 and bears his name. MD is frequently described with "the rule of two". It is found in approximately $2 \%$ of the population, it is located 2 feet $(60 \mathrm{~cm})$ from the ileocecal valve, it is measured as 2 inches $(5 \mathrm{~cm})$ in length and $2 \mathrm{~cm}$ in diameter, it may contain 2 types of common ectopic tissue (gastric and pancreatic), the male/female ratio incidence of $\mathrm{MD}$ is $2: 1$, it is most frequently observed before 2 years of age (2). MD is generally asymptomatic during life and symptoms and can be detected incidentally. Symptoms are observed in around $1 \%$ of patients. MD in the adult patients is diagnosed most frequently with obstruction and bleeding symptoms. Symptoms of MD can be enumerated as gastrointestinal bleeding (20-30\%), intussusception and intestinal obstructions due to volvulus, internal hernias, diverticulitis or perforations 
(3). MD is difficult to diagnose in the preoperative period due to the confusion of the symptoms with many diseases, and only $6-12 \%$ of the cases are diagnosed preoperatively. The cases are usually operated with
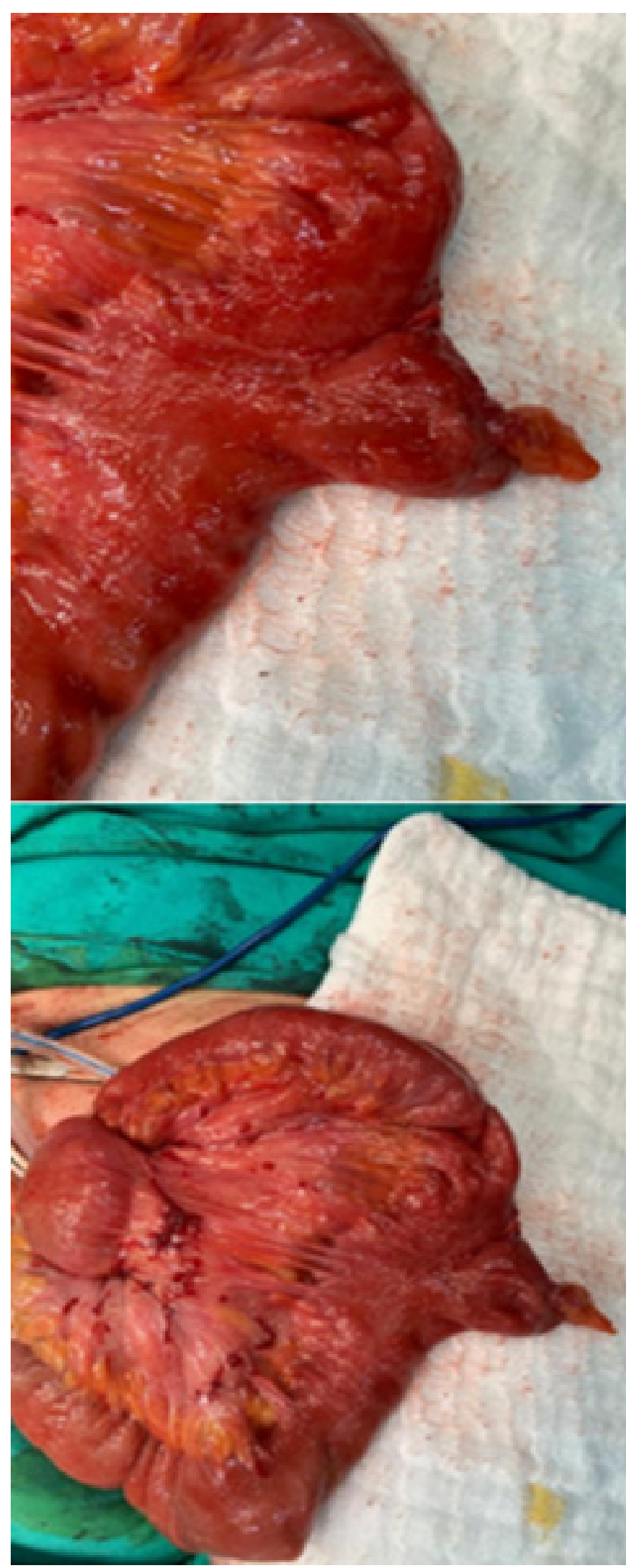

Figure 1. The appearance of the Meckel's Diverticulum in the hernia $\mathrm{sac}$ a preliminary diagnosis of acute abdomen and are generally diagnosed during the operation. It is often confused with appendicitis, gastrointestinal bleeding, and ileus (4).

Incidence of MD within a hernia sac is extremely rare and this unusual condition is known as Littre hernia (LH). $\mathrm{LH}$ is observed in less than $1 \%$ of MD cases (5). $\mathrm{LH}$ is mostly observed on the right side of the inguinal hernia and reported with an incidence of $50 \%$ in inguinal hernia, $19-30 \%$ in femoral hernia, and $12-30 \%$ in umbilical hernia (6). In approximately half of the cases, there is ectopic gastric mucosa tissue. The most important of the complications of this ectopic gastric mucosa is gastrointestinal bleeding. Meckel's diverticula, found by chance during surgery, usually contain an intestinal mucosa. Some diverticula may include gastric, duodenal, colon and, although rarely, pancreatic tissue. The diverticula that most often cause symptoms are those containing gastric mucosa. Bleeding is usually a result of peptic ulcer that develops in the intestinal mucosa due to acid fluid secreted from the ectopic gastric mucosa (7).

The case of Littre hernia, which was first described by Alexis Littre in the early $18^{\text {th }}$ century, is quite few in the literature. In a study by Katsaros et al. (8) Littre hernia case studies, which were published between 1954 and 2018 and mostly after 2008, were examined. The number of cases was reported as 53 in total (21 male and 32 female) and the mean age of the patients was reported as 60. This study revealed that the incidence of Littre hernia cases is very rare.

\section{CONCLUSION}

The presence of diverticulum in a hernia sac is defined as Littre hernia. The case reported in this study is an extremely rare case of Littre hernia, which is seen in around $1 \%$ of $\mathrm{MD}$ cases observed in approximately $2 \%$ of the general population. The diverticulum was imported into abdomen and the hernia was repaired with appropriate technique.

\section{ETHICAL DECLARATIONS}

Ethics Committee Approval: The study was carried out with the permission of Health Sciences University, Hamidiye Scientific Research Ethics Committee (Permission granted: 10/02/2020-Meeting number: 2020/1, Decision number: 20/21).

Referee Evaluation Process: Externally peer-reviewed.

Conflict of Interest Statement: The authors have no conflicts of interest to declare.

Financial Disclosure: The authors declared that this study has received no financial support. 
Author Contributions: Z.Ş. contributed the design, execution, and writing of the case report. T.G. contributed data processing related to the case report.

\section{REFERENCES}

1. Chen JJ, Lee HC, Yeung CY, et al. Meckel's Diverticulum: Factors Associated with Clinical Manifestations. ISRN Gastroenterology 2014; 1-5.

2. Poley J, Thielen T, Pence J. Bleeding Meckel's diverticulum in a 4-month-old infant: treatment with laparoscopic diverticulectomy. A case report and review of the literature. Clin Exp Gastroenterol 2009; 2: 37-40.

3. Huang C, Lai M, Hwang F, et al. Diverse presentations in pediatric Meckel's diverticulum: a review of 100 cases. Pediatr Neonatol 2014; 55: 369-75.

4. Malhotra S, Roth DA, Gouge TH, Hofstetter SR, Sidhu G, Newman E. Gangrene of Meckel's diverticulum secondary to axial torsion: a rare complication. Am J Gastroenterol 1998; 93: 1373-5.

5. Ioannidis A, Karanikas I, Koutserimpas C, Velimezis G. Combined Littre and Richter's femoral hernia: an extremely rare intra-operative finding. Il Giornale di chirurgia 2019; 39:177-80.

6. Lucarini L, Balestrino E, Vassallo G. Strangulation of a Meckel diverticulum in a crural hernia (Littre's hernia). Case report of a male patient. Minn Med 1981; 72: 2997-8.

7. Rashid OM, Ku JK, Nagahashi M, Yamada A, Takabe K. Inverted Meckel's diverticulum as a cause of occult lower gastrointestinal hemorrhage. World J Gastroenterol 2012; 18: 6155-9.

8. Schizas D, Katsaros, I, Tsapralis D, et al. Littre's hernia: a systematic review of the literature. Hernia 2019; 23: 125-30. 